\title{
The Impact of ESA Elements on Motivation of EFL Learners to Speak: A Case of Iranian EFL Learners
}

\author{
Hooshang Khoshsima \\ Chabahar Maritime University, Chabahar, Iran \\ E-mail:khoshsima2002@yahoo.com \\ Hadi Shokri (Corresponding author) \\ Chabahar Maritime University, Chabahar, Iran \\ E-mail: hadishokri2012@gmail.com
}

Received: 13-04-2017

Published: 01-11-2017
Accepted: 02-06-2017

doi:10.7575/aiac.ijalel.v.6n.6p.144
Advance Access Published: September 2017

URL: http://dx.doi.org/10.7575/aiac.ijalel.v.6n.6p.144

\begin{abstract}
Implementing a best course of action to boost English as a Foreign Language (EFL) learners' motivation to speak has been a controversial issue among EFL instructors. The present study aims to investigate the probable impact of Harmer's ESA (Engagement, Study, and Activate) elements implementation on motivation of EFL learners to speak. To meet this objective, first, the pre-treatment questionnaire was delivered to 15 EFL learners at the beginning of the term to measure 'input motivation'. After collecting information from the pre-treatment questionnaire, the students were taught for nearly two months by applying ESA elements, and then the post-treatment questionnaire was given to the same students to gather information of students' motivation changes, students' attitudes towards techniques and activities applied by teachers and their preferences. Additionally, to triangulate the results, a Pearson product-moment correlation coefficient was run to see if there is any relationship between the learners' speaking performance and their motivation to speak. In sum, the results of the questionnaires and correlation analysis proved that the treatment of the learners via ESA approach was quite influential in boosting EFL learners' motivation to speak. It is expected that the findings of the study may significantly contribute to work of EFL teachers, EFL learners, policy makers, supervisors and researchers.
\end{abstract}

Keywords: ESA Elements, Motivation, Speaking

\section{Introduction}

'Motivation is, without question, the most complex and challenging issue facing teachers today.'

(Cited in Dornyei, Z, 2001, p. 1).

The urge to engage learners in learning process seems indispensable and the fact that learner engagement is regarded as intrinsic motivation cannot be taken for granted. Consequently, learner engagement and L2 success is affected by many factors such as age, personality, aptitude, motivation and so on. Among these factors, motivation plays a crucial role (Ellis 1994). For this reason, it was essential to consider learner motivation as an argumentative issue in the present study. The significance of the studies carried out in this field shows the sheer importance of motivation on success or failure of learners involved in the process of language learning.

Multitudinous studies and experiments with regard to human learning have proven that motivation is pivotal to learning in general (Deci 1975, Maslow 1970 and Binalet, C. B., \& Guerra, J. M. 2014). Additionally, Gardner and Lambert (1972) state various studies have found that motivation is very strongly interrelated with learner success and achievement in the process of language learning. However, it remains questionable as to whether motivation is the cause of the learner success or achievement or vice versa. Likewise, it should be clarified which of them is the result of the other. Ur, P (1991) holds that the uncertainty as to which, motivation or success, comes first does not entail any inadequacy or difficulty in the process of teaching. This means that among other activities done in increasing learner motivation, strategies should have high priority.

Numerous studies and EFL instructors utilize approaches and strategies to boost learners' motivation to speak. However, the problems are not alleviated yet and most of them are inadequate and are unable to meet the learners' needs. After the implementation of these methods and strategies, it is made clear that they cannot raise learners' motivation and engagement emotionally, which are the core characteristics of helping the learners to boost their speaking skill. According to what has been stated above, it worth keeping in mind that in the process of being engaged in interactions, especially in warm up and presentation process, learners show factors which contribute to their success or failure in language learning. Hence, for teaching and learning speaking skill, the great importance of learner 
engagement and learner motivation is not an exception and cannot be taken for granted. As a whole, this study is significant owing to the fact that it makes a lot of effort to fill a gap in the field of language teaching and learning and rule out the former studies shortcomings by taking into account student motivation through Harmer's ESA elements.

\section{Literature Review}

\subsection{Elements for Successful Language Learning}

The present language pedagogy practice commonly attempts to cover most of the language teaching elements and tenets. Currently, the language teaching practice frequently gives the learners the opportunity to think about how a piece of conversation is carried out, while at the same time providing for language use in communicative activities. In order to furnish learners with opportunities to use the language more freely, language experts select some parts of the language best elements from a number of different ideas and methods (Harmer 2007). Taking into account the fact that learners need exposure, motivation and opportunities for language use, Harmer (2007) suggests that most teaching sequences need to have certain features or elements. These elements are engage, study and activate.

\subsubsection{Engage}

The principal objective of engagement phase requires teachers to elicit learner's curiosity, engagement, attention, emotion and interests. In this phase, teachers can utilize a variety of warm up activities including games, interesting anecdotes, storytelling, recordings, picture descriptions etc. Harmers (2007) state that "unless students are emotionally engaged with what is going on, their learning will be less effective" (p.66).

\subsubsection{Student engagement}

Student engagement is the current and developmental field of study and the finding are quite challenging. Shulman (2002) stresses on the nature of student engagement and holds that "learning begins with student engagement" (p.37). In any learning situation, specifically in classroom setting, any achievement without considering learner engagement would lead to incomplete conclusions or results. Williams and Milton (2009) divide student engagement into three levels: behavioral engagement, emotional engagement and cognitive engagement.

The focal attention of behavioral engagement is principally on the tenet of participation and involvement of learners in social and academic activities required for achieving positive outcomes.

Emotional engagement refers to the learner's reaction toward the teacher, classmate and the academic course. Learners participating in class exhibit positive and sometimes negative attitude or reaction. These emotions include: boredom, happiness, interest, anxiety, stress, etc.

Cognitive engagement is the amount of time, effort, desire, attentiveness and strategies exercised and applied by learners required for comprehension of complex ideas in carrying out tasks.

Prince (2004) believes that student engagement is associated with positive learning outcomes. In the same manner, Kinzi (2010) describes the association between student engagement and academic success as follow:

A consequential body of research implies that once students begin studying at a college or university a key factor as to whether they will put considerable amount of effort and strive to participate in educationally meaningful activities is largely dependent upon the extent to which they are engaged in academically well-structured environments. Quite simply, to make certain how many students graduate and make the most of their undergraduate and postgraduate education, university faculties need to first assure the learning environment offer prolific and educationally mindful opportunities and subsequently concentrate precisely on promoting student engagement.

Hughes and Pace (2003) studies show that the reason why most learners do not attend or leave university prematurely is that they are less engaged than their peers. Additionally, Kuh (2001) holds that "student engagement pictures both time and effort students put in educationally meaningful activities and the potential energy language departments allocate using productive educational rehearsals.

\subsubsection{Student Engagement, Motivation and Active Learning}

Elizabeth F. Barkley (2010) points out that motivation and active learning elements of student engagement are both required for meaningful learning. To make her saying understandable, she gives the following example:

A classroom which is full of exuberant, interested and motivated learners is fantastic, but it seems educationally pointless if the exuberance does not lead to active learning. On the contrary, students who are resolutely engaged in the process of learning but do so unwillingly and rancorously are not engaged. She further points out that student engagement is the product of motivation and active learning. To make it more clearly understood, she states that student engagement does not occur if either element is missing. That is, it does not result from one another, but rather is generated in the space that resides in the overlap of motivation and active learning.

According to the abovementioned statements, Elizabeth F. Barkley (2010) proposes a definition within the context of a college classroom and points out that "student engagement is a process and a product that is experienced on a continuum and result from synergistic interaction between motivation and active learning" (p.8). Bonwell and Eison (1991) define active learning as "doing what we think and thinking about what we are doing" (cited in Elizabeth, Barkley, p.6). Elizabeth, F. Barkley (2010) indicates that active learning is the total active engagement of mind. Its features involve learners' dynamic participation in the process of learning. Other features include monitoring and reflection on the tasks and discussions they are engaged in. 


\subsubsection{Study}

The study phase of ESA mainly focuses on language usage. The tasks at this phase center on forms of the language and the information about how it is formed. This phase entails focus on learner-led grammar discovery, eliciting grammar from learners rather than teacher-led presentations. These may include specific intonation patterns, a specific relative clause or the way a lexical phrase is made or used (Harmer, 2007).

\subsubsection{Activate}

Regarding activate phase of ESA, learners are engaged in more communicative and meaning-focused tasks. As an example, communicative tasks are particularly designed to activate the learners' language competence (Harmer, 2007). He believes that the more learners have chances to activate the several elements of language they have kept in their minds, the more autonomous their use of these elements would be. Correspondingly, learners regularly become autonomous language learners and language users. It means that they can use words and phrases systematically and fluently without giving it much thought. Harmer believes that successful language learning is heavily grounded on a sensible integration of subconscious acquisition of language. Activation is the goal of most classroom teachers. Since it gives information about the learners learning process and the teacher can discover what the students' problems are and can give necessary remedial work. A universally used activation technique in teaching is questioning. This technique is mainly used within the Initiation-Response-Feedback pattern. Some may ask the reasons why a teacher should ask question in the classroom. Ur, P (1991, P.229) provides various reasons of asking questions used in activating learners' knowledge:

- To provide a model for language or thinking.

- To find out something from the learners (fact, idea, opinion).

- To check or test understanding, knowledge or skill.

- To get learners to be active in their learning.

- To draw attention to the theme being acquired.

- To provide weak learners with an opportunity to participate.

- To encourage self-expression.

- To get learners to review and practice previously learned material.

Another technique used in activating learners' language knowledge which is a more valuable tool in oral fluency work is called 'group work'. In this type of activity learners carry out a learning task through a group work activity. Ur, Penny (1991) hold that this type of activity in contrast to other activities like full-class size activity has got several advantageous; he states that learners in class split into five groups get five times as many chances to speak.

\subsection{Motivation}

Motivation as an abstract term has no definite definition on its own. Therefore, it is more easy and convenient to think of it in terms of learner motivation. Ur, P (1991) says that motivated learners are those who are willing or more eager to invest time and effort to learn new things and progress. Dornyei, Z and Ushioda, E (2011) say that 'the word motivation stems from the Latin verb movere holding the sense of 'to move'. They also state it can be regarded as what encourages a student to make certain choices, to get involved in action, to put high effort and perseverance in action" (p. 3). Dornyei and Otto (1998) define motivation in a general sense as:

"the dynamically changing cumulative arousal in a person that initiates, directs, coordinates, amplifies, terminates and evaluates the cognitive and motor processes whereby initial wishes and desires are selected, prioritized, operationalized and (successfully or unsuccessfully) acted out (p.65).

Similarly, Brophy (2004) gives another distinctive definition of motivation in the classroom setting, he indicates that motivation in the classroom is "the level of enthusiasm and the degree to which students invest attention and effort in learning" (p.4).

\subsubsection{Motivation in Classroom Setting}

Lightbown and Spada (1999) assert that teachers can make a positive contribution to learners' motivation to learn by making their classroom a place where they enjoy attending, because the classroom's content is more fun, interesting and relevant to their age and level of their capabilities. In this case, their learning goals are made challenging and clear. Moreover, this process will make the classroom atmosphere supportive and non- threatening. Crookes and Schmit (1991) point out some pedagogical practices for teachers to motivate students in classroom setting:

- Motivating students into the lesson: At the opening stages of lessons, remark teachers make about approaching activities can result in higher levels of enthusiasm on the part of the students.

- Modifying the activities, tasks and materials: Lessons which invariably comprise of the same procedures, patterns and format commonly result in a decrease in consideration and an increase in wearisomeness. Modifying the activities, tasks, and materials can assist to shun this and increase students' interest to a great extent.

- Employing co-operative instead of competitive goals: Co- operative learning activities involve activities in which students have to work together so as to complete a task or find a solution to the problem. These techniques will promote the self- confidence of students, especially the weak students. 
Although practices are effective techniques in motivating students, there are some students who are less engaged and are unwilling to speak up in the class. Tsui (1996) found out five main factors affecting the unwillingness of the learners to speak up in class:

- learners' perceived low proficiency in English

- learners' apprehensiveness of mistakes and contempt

- instructors' intolerance of unresponsiveness

- uneven allocation of turns

- incomprehensible input

(Cited in Nunan, 1999, p. 234)

\section{Methodology}

In order to determine learners' motivation, quantitative method was utilized. The data collected for the study come from 15 learners participating in the experimental group answering the pre-treatment questionnaire and the same 15 learners participating in the same group answering the post-treatment questionnaire. In this process, each person's answers in the pre-treatment questionnaire will be differentiated with the same person's answers in the post-treatment questionnaire. The purpose of distributing these questionnaires is to make sure whether application of ESA approach on tasks is helpful in developing EFL learners' motivation to speak.

Additionally, -in order to triangulate the results of the study- the correlation was run to see whether there is a relationship between the method used and motivation of learners to speak. Correspondingly, after the treatment students were given a First Certificate in English (FCE) speaking test to examine if there is any relationship between the learners' speaking performance and their motivation to speak.

As noted earlier, the design of the study is quantitative in nature and seeks to find out whether implementation of ESA elements is helpful in improving motivation of EFL learners to speak or not.

\subsection{Subjects}

In this study, 15 participants both male and female were chosen from Chabahar Maritime University majoring in English translation. They had the same amount of exposure to English language learning. All of the subjects are studying English as L2 language and are native speakers of Farsi. Learners received two sessions of study every week; each session lasted 40 minutes for nearly 12 sessions.

\subsection{Data Collection Instrument}

For the purpose of the study, before and after the experiment, the researcher distributed motivation questionnaires to the learners in experimental group to make certain how much the techniques applied in the class were useful in affecting their motivation to learn.

In conducting the study, the following instruments were used: a pre-post treatment survey questionnaire given to the experimental group, an FCE speaking test taken from Official Examination Papers from University of Cambridge English for Speakers of Other Languages (ESOL) Examinations (2008).

\subsubsection{Pre-treatment Questionnaire}

The pre-treatment questionnaire items were taken from LAN (2008) and it had two main parts with 13 questions. Part one which is the main focus of the study included their opinions about their motivation in learning speaking English. Students' motivation was measured with their aptitude, interest, attitude, desire and effort in learning. Part three attempted to collect the main information about the factors affecting learner motivation in learning speaking English.

\subsubsection{Post-treatment Questionnaire}

Post-treatment questionnaire comprised 15 questions which were divided into two parts. Part I included 10 questions which would gather information about students' motivation alteration after the implementation of ESA approach in mastering the EFL learners speaking skill. Part II intended to collect information about teacher's implemented activities in teaching speaking English and students' preference of these activities.

\subsection{Validity and Reliability of the Questionnaire}

The main aim of the study is to determine the extent of ESA elements implementation effect on EFL learner's motivation to speak. Correspondingly, in order to meet the objectives of the study prior to the data collection process, the questionnaire proposed was taken from LAN, L. T. (2008). The adapted questionnaire was given to two teaching English as a foreign language (TEFL) instructors in Chabahar Maritime University to evaluate the items analytically in terms of content validity, face validity, comprehensibility of the items and if they fit to measure the objectives of the study.

Consequently, in order to check the internal consistency of the questionnaire results, a pilot study was conducted in Tehran language school. The participants involved in the pilot study were not included in the sample during the administration of the final form of the questionnaire. The reliability of the test instrument was tested by Cronbach alpha method. The calculated Cronbach alpha of the test instruments were 0.71. Thus, the instruments were found to be reliable to collect data for the main study. 


\subsection{Procedures}

The procedure involved in conduction of this study attempts to see whether utilization of ESA elements in tasks have significant effect on improving motivation of Iranian EFL learners to speak. To meet this objective, first, the pretreatment questionnaire was delivered to students of experimental group at the beginning of the term to measure 'input motivation'. After collecting information from the pre-questionnaire, the teacher taught the students for nearly two months with applying ESA elements on tasks involved in teaching of speaking, and then the post-questionnaire was given to the same students to gather information of students' motivation changes, students' attitudes towards techniques and activities applied by teachers and their preferences. To analyze the collected data, frequency of both pre and post treatment questionnaire were differentiated to see whether the treatment has improved their motivation or not. Significantly, in order to have a better differentiation and analyze carefully the motivation of the EFL learners, a Pearson's Product-Moment Correlation Coefficient (PPMCC) between the sores of the learners speaking performance and post-treatment questionnaire motivation was run to see any significant improvement.

\section{Data Analysis}

In order to analyze the data, a pre-treatment questionnaire was handed out among the students before the treatment and the results were shown using the descriptive method and frequencies, then after the treatment the student were given a post-treatment questionnaire and the data were shown through the descriptive method and frequencies as well to see any improvement caused by the treatment. The date analysis concerning this research involves 3 stages of conduction. In the first stage, both pre-treatment and post-treatment results are analyzed using frequencies. In the second stage, students speaking performance and students post-treatment questionnaire scores are analyzed to see if the scores of the both tests are reliable to be used in the study. In the third stage, a correlation between the speaking performance scores and the same students posttreatment questionnaire scores was run too see the extent to which they are relevant or correlate.

\subsection{Results from Student's Pre-treatment Questionnaire}

In order to see if the application of ESA elements on tasks has significant effect on motivation of learners to speak, the study used two types of questionnaire. The first one was handed out at the outset of the study before the treatment and second one after the treatment. The pre-treatment questionnaire shows the detailed motivation of learners to speak before the treatment. The data gathered are presented using frequency of the learners.

\subsubsection{Students' motivation in learning speaking English}

\section{Q1. Why do you want to learn English speaking?}

Students who learn to speak English have distinct types of motivation which vary among them. They include: integrative, instrumental, intrinsic and extrinsic motivation. The table below shows the students motivation type.

Table 4.1 Types of motivation

\begin{tabular}{lll}
\hline Reasons & Students & Percentage \\
\hline To get higher marks & 3 & $20 \%$ \\
\hline Interest in English language, people and culture & 4 & $27 \%$ \\
\hline To sing and listen to English songs & 5 & $33 \%$ \\
\hline For the future job & 11 & $73 \%$ \\
\hline To study abroad & 6 & $40 \%$ \\
\hline
\end{tabular}

Table 4.1 reveals that most of the students wanted to learn English for their future job. That is, $73 \%$ of the students have instrumental motivation, though the reason can be the fact that they are all students of English translation. Nearly $40 \%$ of the students affirmed that they want to learn English in order to be able to get the opportunity to study abroad. Only about $20 \%$ of the respondents claimed that they study English to get higher marks.

\subsubsection{Students' Opinions on Learning Speaking English}

\section{Q2. How is speaking skill important to you?}

High percentage of students $(60 \%)$ responded that speaking was quite important. The reason seems that since they are students of English translation and as noted earlier they are extrinsically motivated. That is, they study to get future jobs. Only about $27 \%$ of the respondents considered speaking skill rather important and $13 \%$ of the students claimed the significance speaking skill as normal.

\section{Q3. How is your aptitude to learn speaking English?}

The learner's responses to their estimated aptitude were quite interesting. $47 \%$ of the responses confirmed that the student's aptitude level is ok. Nearly about $27 \%$ of the respondents claimed that their aptitude level is high, while only about $20 \%$ considered their aptitude level as low. Considering the frequencies, it can be deduced that learner's aptitude to learn speaking English is quite normal.

\section{Q4. How is your attitude to learn English speaking?}

The student's responses are the strongest proof to state that most of the learners' attitude toward learning to speak English is quite normal. Having the abovementioned claim in mind, the frequency of the students who confirmed that 
they have very high opinion of learning to speak English is $20 \%$ and likewise $20 \%$ of them claimed high as well. On the other hand, $40 \%$ percent claimed that their attitude is ok and another $20 \% \%$ of the learners claimed they have a low opinion of learning to speak English. Therefore, it can be claimed for sure that the students' attitude toward learning speaking English is normal.

\section{Q5. How is your effort in learning speaking?}

Regarding the fact that learners confirmed that they have a positive high opinion of the learning speaking, but their effort in learning speaking did not match their attitude. $40 \%$ of the participants agreed that their effort in learning speaking is ok. And nearly about $27 \%$ of confirmed that they have a high tendency to put effort in learning to speak. $20 \%$ of the respondents argued that they put a very high effort in learning speaking and only 13\% showed low motivation to put effort in learning speaking.

Q6. How is your desire to learn English speaking?

In this case, $60 \%$ of the respondents argued that they have a very high desire to learn to speak English. $27 \%$ had high desire and only 13\% claimed ok. Therefore, it can be deduced that they need to put an effort in learning to speak fluently.

\section{Q7. How much do you feel interested in speaking English in class?}

The students' answers reveal that most of them are very eager to express their ideas in class. That is, $47 \%$ had high interest and $40 \%$ of them had rather preferred to speak and only $13 \%$ showed normal interest in speaking in class. And none of them had ticked little or no interest to express themselves.

\section{Q8. How often do you speak English in English class time?}

The frequency with which students speak in class time with the frequency of their interest depicts the fact that although they are highly interested in speaking in class, they are given less time or opportunity to express them. The reason may determine the fact that that they are less motivated or engaged in tasks or activities carried out in class time during their speaking course. The frequency of students who always spoke in class time was $13 \%$, those who usually spoke responded as $20 \%, 40 \%$ responded sometimes and $26 \%$ rarely spoke in class time.

\subsubsection{Factors Making Students Reluctant to Speak English in Class}

\section{Q9. Do you feel reluctant to speak English in class?}

Students' willingness to speak in class was quite interesting, since they were very eager to express themselves freely without any difficulties. 33\% said that they like English very much. 33\% other said that they were willing to speak, 20\% responded sometimes and the other $13 \%$ responded that they are often unwilling to speak.

Q10. What do you think about the topics discussed in the class?

There is a very strong correlation with students' willingness as well as interest and the topics discussed in the classroom. If the students are not interested in the topics, most probably they are not willing to speak up in class time. The frequency of the responses denotes that $33 \%$ of the students found the discussed topics in class boring. $27 \%$ said that the topics were ok. $20 \%$ of them found interesting and the other $20 \%$ were very interested in the topics.

\section{Q11. What do you think about speaking tasks done in the class?}

Speaking tasks are among the factors which give variety to the teaching speaking class. Therefore, the teacher must use a wide variety of tasks and activities to engage or sometimes get them motivated throughout the whole process of teaching. It can also be perceived that tasks play a major factor in getting the students engaged, interested, willing and motivated. Likewise the teachers must rough tune the task difficulty with the students' level so as not to bore or make them uninterested in the activities of the task. $47 \%$ said that the tasks' difficulty were ok. $40 \%$ claimed difficult. $13 \%$ responded as too difficult and $13 \%$ asserted that the tasks very easy to carry out. Therefore, most of the students confirmed that the tasks done in their class was ok.

\subsubsection{Factors Affecting Students' Motivation in Learning Speaking English}

\section{Q12. Which of the following factors make you reluctant to speak English in class?}

There are quite unlimited factors that can contribute to the student's unwillingness to speak. They may range from the learner and teacher factors to teaching learning conditions. Herby, only the teacher and learner factors will be examined. Table below depict the frequency of the factor which contributed to the students unwillingness to speak English in class.

Table 4.2 Factors making students reluctant to speak English in class

\begin{tabular}{lll}
\hline Factors & Students & Percentage \\
\hline Fear of mistakes and derision & 10 & $67 \%$ \\
\hline Low proficiency in English & 6 & $40 \%$ \\
\hline Being not accustomed to speaking English in class & 4 & $27 \%$ \\
\hline Uneven allocation of turns & 3 & $20 \%$ \\
\hline Teacher's boring teaching & 8 & $53 \%$ \\
\hline Teacher's intolerance of silence & 4 & $27 \%$ \\
\hline
\end{tabular}


The table 4.2 represents the reasons that contribute their unwillingness to speak. The first and foremost significant factor which must be emphasized is their fear of mistakes and derision. $67 \%$ of the respondents claimed that they wanted to speak, but they feared of making mistakes and get ridiculed. The second factor shows that most of the students did not approve their teacher's method of teaching. This may denote the fact that the teachers must use games, tasks, activities, variety of teaching techniques and methods in their classroom. 53\% of the students claimed that their teachers boring teaching resulted in their unwillingness. As a concluding remark, it is made clear that both the teacher and learner factor contribute to the learners speaking unwillingness process. Therefore, changes need to be applied for both the teacher and learners. The teachers must alter their teaching process and the learners must alter the way they precede learning to speak.

Q13. Which do you think often prevents your speaking English process?

Table 4.3 Factors preventing students' speaking process

\begin{tabular}{lll}
\hline Factors & Students & Percentage \\
\hline Unable to find words or structures & 9 & $60 \%$ \\
\hline Unable to find ideas & 8 & $53 \%$ \\
\hline Teacher's unenthusiasm & 3 & $20 \%$ \\
\hline Teacher's interruption or anger & 4 & $27 \%$ \\
\hline Too much teacher's talking time & 5 & $33 \%$
\end{tabular}

Perceived from the table, it can be argued that most of the learners, which mean $60 \%$, are unable to find words or structures to get their message crossed. Now, it can be claimed that not only teachers should provide the learners with each lessons new words and structures, but also they obliged to teach and present some other simple words and fixed phrases that can assist learners to have more information about the topic and the task they are going to express by words. Another factor which seems to be rooted in their background knowledge is the extent to which they cannot find ideas. Therefore the topics discussed in the classroom must be made according to the learners' interest and need.

In summary, the results and findings of the pre-treatment questionnaire reveal that student's motivation to speak English was ok. Clearly, some of them were highly motivated and put effort and time in their learning process. These students were very conscious about their learning process and controlled all the negative factors that can inhibit their speaking process. On the other hand, most of the student's responses denoted the fact that the teachers are responsible for their learning speaking process. Consequently, quite a large number of students were reluctant to speak English in class time. Therefore, in order to get the learners more interested, willing and motivated to speak English, students were instructed a two month period teaching. They were taught by applying Engage, Study and Activate (ESA) elements on tasks in mastering their speaking skill. It was claimed that this type of treatment would boost their speaking skill proficiency. Hopefully, the results of the post-treatment questionnaire revealed some positive results. That is, this type of instruction encouraged learners to speak rather fluently in class.

\subsection{Results from Student's Post-treatment Questionnaire}

After concluding the results of the student's pre-treatment questionnaire, the students were instructed in a two month period through applying ESA elements in increasing their motivation to speak up in the class. Then, when the treatment was over, they were given a post-treatment questionnaire to estimate their increase in their motivation to speak. The post-treatment questionnaire is divided into two parts. The first part investigates student's motivation in learning speaking English. And the second part is solely dedicated to investigate the factors that can contribute to the learner's motivation as well as their attitude toward the techniques and the strategies applied by the teacher.

\subsubsection{Student's Motivation in Learning Speaking English}

\section{Q1. How is speaking skill important to you?}

After the treatment, the number of learners who claimed that speaking skill was important increased from $60 \%$ to $73 \%$. However, the percentage of students who considered speaking skill as normal decreased to $7 \%$. Therefore, most of the students affirmed the significant role of speaking as the prerequisite to their future success in language learning.

\section{Q2. How is your aptitude to learn speaking English?}

Surprisingly, the number of students who did not trust in their full potential in learning speaking English before the treatment increased after the treatment. The students who responded with very high aptitude increased from $7 \%$ to $13 \%$. Likewise, the students who chose high aptitude also increased from $27 \%$ to $47 \%$ which shows $20 \%$ increase in their aptitude level. Accordingly, students who did not believe in their capability to learn speaking English decreased from $20 \%$ to $7 \%$ which shows that $13 \%$ of the students trusted in their ability to learn speaking English after the treatment.

\section{Q3. How is your attitude to learn speaking English?}

Students' stance or feeling toward learning to speak English was quite normal before the treatment. But, after the treatment their position has changed significantly. The students' attitude toward learning to speak which was normal decreased from $40 \%$ to $27 \%$ while the students with high attitude increased from $20 \%$ to $33 \%$. 
In terms of endeavor, before the treatment learners attempt to learn speaking was very normal. To a greater extent, it can be deduced from the first question of pre-treatment questionnaire about their motivation that their effort to learn to speak English has much common with their instrumental motivation to get a better future job. Noticeably, after the treatment there was an increase in the frequency of the responses with high effort. It increased from $27 \%$ to $33 \%$ which shows that students showed better eagerness in exerting more energy in approaching their schoolwork speaking tasks. As a concluding remark of this question, it seems needless to state that student engagement in tasks significantly has boosted their interpersonal relationships.

\section{Q5. How is your desire to learn speaking English?}

When it comes to students' inclination and craving to speak up in class, most of them are very eager to show up and express their ideas, opinions, and feelings. Before the treatment, 60\% of the learners had a very high desire to learn speaking English and stunningly none of them showed lack desire to speak up in class time. In similar fashion, after the treatment there was a $13 \%$ increase in their longing to learn speaking English with very high desire.

\section{Q6. How much do you feel interested in speaking English in class?}

It seems indispensable to state that student's interest in speaking English is relevant to their desire to learn speaking English. With regard to the twelfth question of the pre-treatment questionnaire, $53 \%$ of the students claimed that their boredom was the result of the teacher's boring teaching. However, students' with very interest in speaking English in class increased from $47 \%$ to $53 \%$. In contrast, there was a $6 \%$ decrease from $13 \%$ to $7 \%$ with regard to students whose interest was normal.

\section{Q7. How often do you speak English in English class time?}

It is undeniable to assert that alterations in students' interest and desire would lead to the alterations in students' engagement in class discussion. The frequency of learners who never participated in class discussion, reduced to $13 \%$ from $26 \%$ to $13 \%$. On the contrary, the number students who usually were engaged in class discussion increased noticeably. This alteration increased from $20 \%$ to $40 \%$. In addition, the changes also were applied to the frequency of students who claimed that they sometimes speak in class time decreased from $40 \%$ to $33 \%$.

\section{Q8. Do you feel reluctant to speak English in class?}

Astonishingly, the number of students who were unwilling to participate in class discussion decreased dramatically after the treatment. Before the treatment, $13 \%$ of the students claimed that they often feel reluctant to speak up in class time. On the contrary, after the treatment none of the students were reluctant to get engaged in class discussion. Moreover, before the treatment 33\% of the learners affirmed that they like speaking English, but this percentage increased to $40 \%$. It would also suffice to state that there was a $14 \%$ increase in the number of students who said that they speak willingly.

\section{Q9. What do you think about the topics discussed in the classroom?}

Making recourse to the questions which estimated learners' interest, reluctance and desire, it seems logical to hold that the said factors have much in common with the topics discussed in class. There was a meaningful change in the students' responses. Before the treatment, 33\% found the discussed topics in class boring. On the other hand, after the treatment this percentage decreased to $13 \%$. Besides, the number of respondents who were very interested in the topics increased from $20 \%$ to $27 \%$. Likewise, students who found the topics interesting increased from $20 \% 33 \%$.

\section{Q10. What do you think about speaking tasks done in the class?}

The number of students who claimed that the speaking tasks were ok remained constant. However, $13 \%$ of the learners found the task done in the class easy before the treatment, but after the treatment $20 \%$ claimed that the tasks were easy. Furthermore, before the study, 26\% of the students found the tasks done in their speaking classroom difficult. However, this number decreased to $13 \%$ after the treatment.

\subsubsection{Factors Increase Students' Motivation in Speaking English}

\section{Q11. What results have you achieved through the recent lessons?}

The findings reveal that the majority of students $(53 \%)$ agreed on the fact that their speaking proficiency has increased during the treatment course. Obviously, when the speaking tasks like discussion and decision, dialogues and role play, questioning- answering and interview, picture and picture story as well as activities like pair and group work were applied, their engagement required them to activate information-gap, opinion-gap and problem solving abilities which leaded to better speaking performance of the participants. As a result, students with better performance had many opportunities to speak up and exchange information with the weaker ones. The superiority of these tasks lies in the fact that the practicing time and student talking time benefited student to have much opportunity to engage in the discussions. Noticeably, this was the reason why most learners felt more self-confidant and interested in speaking English (46\%). Another contribution to this fact resulted in students' eagerness to speak up in class (40\%). And the number of students who realized that speaking English is not difficult changed their mind in a very positive fashion, $33 \%$ and 26\% hold that their English knowledge has been broadened. Other students (13\%) specified that they need more time and instruction to improve their speaking proficiency skills. 
Q12. Which of the following factors may encourage you to speak English in class?

Table 4.4 Factors encouraging students to speak

\begin{tabular}{lll}
\hline Factor & Student & Percentage \\
\hline Interesting topics in the textbook & 6 & $40 \%$ \\
\hline Teacher's good characteristics (enthusiasm, helpfulness, friendliness...) & 5 & $33 \%$ \\
\hline Teacher's teaching methods & 8 & $53 \%$ \\
\hline Pleasant class atmosphere & 4 & $27 \%$ \\
\hline Various speaking activities & 8 & $53 \%$ \\
\hline High oral marks you may get & 2 & $13 \%$ \\
\hline
\end{tabular}

There is no surprise that most of the students (53\%) agreed on teachers teaching methods and various speaking activities performed during the treatment. Therefore, it can be said for sure why they responded like this. More probably, the justification accounts for their participation and engagement in tasks and activities applied by the teacher. It would suffice that the teaching methodology applied in the classroom resolved the inadequacy of the previous studies to a greater extent. Since in the engagement phase, the student's total participation and involvement in tasks were made easier by holding discussion activities and so on. Likewise, in the study phase, students' accuracy was proofread by performing inductive and discovery activities designed by the teacher by making recourse to their course book. Finally, by doing some activation tasks, like questioning, pair and group work, the teacher received feedback about how much the students have learned and where more instruction was needed. In this case, the teacher monitored the students' performance and corrected their errors in an unthreatening manner. The correction is done indirectly by providing a question with a rising tone, giving two alternatives or asking their peers to correct. Most of the students get bored and uninterested in speaking English when they find the topics boring. As a result, teachers should make use of meaningful and authentic materials to get them engaged and interested in the topic. Besides, the teachers must also be conscious about selecting tasks and activities. $40 \%$ of the respondents said that interesting topics encourage them to speak English in the classroom. Students only speak up when they feel calm and confidant. Not only they like to discuss and communicate with their peers, but also they are eager to express their opinions and feelings with their teacher. This can be facilitated through the teachers' enthusiasm, helpfulness and friendliness. 33\% confirmed that their teacher's good characteristics encouraged them to speak up in the class.

Q13. In speaking lesson, which of the following activities does your teacher often use to motivate you and which do you feel enjoyable?

Table 4.5 Activities applied by the teachers and students participation

\begin{tabular}{lll}
\hline Speaking activities & $\begin{array}{l}\text { Activities applied by } \\
\text { teacher }\end{array}$ & Activities you enjoyed \\
\cline { 2 - 3 } & Percentage & Percentage \\
\hline Completing dialogue practice & $7 \%$ & $27 \%$ \\
\hline Role play & $87 \%$ & $67 \%$ \\
\hline Interview & $67 \%$ & $47 \%$ \\
\hline Games & $40 \%$ & $73 \%$ \\
\hline Free discussion and problem solving & $67 \%$ & $93 \%$ \\
\hline Structure-based activities & $33 \%$ & $27 \%$ \\
\hline Making up sentences orally & $20 \%$ & $20 \%$ \\
\hline Question and answer exchanges & $80 \%$ & $67 \%$ \\
\hline Picture description & $93 \%$ & $87 \%$ \\
\hline Ranking exercises & $0 \%$ & $0 \%$ \\
\hline Story telling & $0 \%$ & $7 \%$ \\
\hline
\end{tabular}

Table 4.5 reveals that free discussion and problem solving activities (93\%) is preferred by the students as their first ranking. They enjoyed more from the activities which they can express more thought, opinion, etc. The reason concealed behind this fact may prove that interpersonal activities like this would boost their social behavior to become part of the society. $87 \%$ of the students held that they were interested in visual aids like pictures, maps and so on. In this case, it seems logical to state that students prefer to get in touch with real life materials and language use, since they provide realistic situations. Hopefully, $93 \%$ of them affirmed the teacher use of this material in the classroom. In terms of games, $40 \%$ of the students held that the teacher did not make use of the games in the class, though they enjoyed doing very much (73\%). The reason lies in the fact that these types of activities are time-consuming and are not 
worthwhile to be applied in speaking classes. Role play and question and answer exchanges play the fourth factor in students' likening (67\%). This preference may be due to the fact that this type of activities does not need teachers more interference of the task and they can freely communicate with their peers in a very safe situation. Learners chose interview (47\%) as their fifth preferences. Although the first part of the class was dedicated solely to the interview $(67 \%)$ due to its occurrence in their final FCE speaking test, they did not approve of it very much. Therefore, it can be deduced that interviews put students in an uncomfortable situation which gives students stress, anxiety and lack of selfconfidence. Other factors like completing dialogue practice, Storytelling and ranking exercises were rarely preferred and used by the teacher in the speaking English classroom (27\%, 7\% and 0\% respectively).

As the concluding remarks of the present question, it seems needless to assert that most of the activities and tasks as well as topics discussed in speaking English classrooms must be presented according to students' needs and preferences. Consequently, it can be argued for sure that they enjoy the type of activities in which they can express their feelings, opinions freely in a very nonthreatening situation where they feel less stress and anxiety. In addition, real life and authentic materials which portrait the real use of the language is also a motivating factor in students likening to speak up in English speaking class.

Q14. Which of the following activities do you like most in a speaking lesson?

$47 \%$ of the students agreed on group work which means they prefer to work on activities which provoke their engagement in interpersonal relationships and make them as part of the social community taking responsibilities. This may also be due to some psychological factors. These may entail lack of stress, anxiety, feeling of fear, loneliness, boredom, reluctance and so on. Role play occupies the second ranking among students' most likening activities (33\%). As such, the reasons may entail its feature as being the simplest form of activity which consumes less energy and needs only two participants. In this type of activity students get engaged in question and answer exchanges, role play and task completion activities. Individual work $(20 \%)$ is the least favorable type of activity preferred by the students.

Q15. Which of the followings do you think your teachers should do to motivate you to take part in speaking activities?

Table 4.6 what teachers do to motivate students to take part in speaking activities.

\begin{tabular}{ll}
\hline Teachers job & Percentage \\
\hline Not interrupting you when you make mistakes & $47 \%$ \\
\hline Accepting a variety of your answers & $40 \%$ \\
\hline Encouraging you with marks and rewards & $27 \%$ \\
\hline Being enthusiastic, friendly and helpful & $80 \%$ \\
\hline Creating some interesting games and activities & $67 \%$ \\
\hline Creating pleasant class atmosphere & $40 \%$ \\
\hline Having clear instructions & $33 \%$ \\
\hline
\end{tabular}

Having a quick look over the table 4.6, it is revealed that the majority of the students (80\%) came to the terms that teachers' enthusiasm, friendliness and helpfulness play a major role in their motivation to get engaged in speaking activities. Generally speaking, making a convenient and non-threatening situation for students is a must. Having a meticulous look at the previous tenets of the study as to psychological factors such as anxiety, stress, fear, interest and so on, there is no doubt to stress the essentiality of the principles of teachers good manner an characteristics. Fun, games and variety are the indispensable part of any language teaching and pedagogy. These principles are also in line with the principles of active learning, student engagement and motivation. $67 \%$ of the respondents agreed on this. Mistakes and errors represents that student are learning. They get discouraged when they are interrupted and corrected on the spot when their total focus is on fluency activities. Therefore, teachers should correct their mistakes indirectly in a very supporting manner or postpone correcting them during conduction of some accuracy-based activities. $47 \%$ of the respondents agreed on the terms of not being interrupted when they make mistakes.

In short, a meticulous scrutiny over the post-treatment questionnaire findings will reveal some fascinating results. Certainly, the findings are strictly grounded in the fact that students speaking English and active learning has much to do with their motivation to learn. Unless, their motivational needs are not met, learning to speaking English would lead to some inconclusive consequences. Therefore, putting their preferences forward by providing a situation where they feel their needs are met, can overcome the inadequacies of difficulties in learning to speak English.

Comparison of the pre-post treatment questionnaire confirms that the tenets of the approach being taken in the classroom, application of ESA elements in boosting speaking proficiency, is in line with the principles of the students preferences, likening, interests, desires, active learning and motivation. Correspondingly, it also proves that there is a significant alteration in learning to speak of the students after the treatment.

\subsection{Reliability of Test Scores}

In any research conduction, consistency of test scores must be determined in advance. In the same manner, this study also calculates the reliability of the test scores to make sure that the scores are consistent. Considering the reliability 
analysis, the scores of the students' speaking posttest and post-treatment questionnaire are measured through Cronbach reliability analysis.

Table 4.7 Reliability Statistics

\begin{tabular}{ll} 
Cronbach's Alpha & N of Items \\
\hline .847 & 2 \\
\hline
\end{tabular}

Regarding table 4.7, it reveals that the estimated Cronbach alpha measurement equals .847 which shows that the test scores of the speaking posttest and post-treatment questionnaire are consistent. Hence, the test scores of the study are reliable enough to be used in the study.

\subsection{Correlation Analysis of learners speaking performance and Motivation}

In order to explore whether there is any significant relationship between speaking performance and motivation, a series of computations and statistical analyses was performed.

In approaching the data analysis, two types of statistics namely descriptive and inferential, were utilized. Regarding the descriptive statistics of the study mean, SD and standard error of measurement were used. On the other hand, concerning the inferential statistics a Pearson's' product-moment correlation coefficient (PPMCC) analysis was run. Additionally, in order to validate the use of this parametric correlation, the linearity of both Variables were examined.

\subsubsection{Linear Relationship between Variables}

To examine the linearity of the relations, a scattergram was generated which is shown in Figure 4.1.

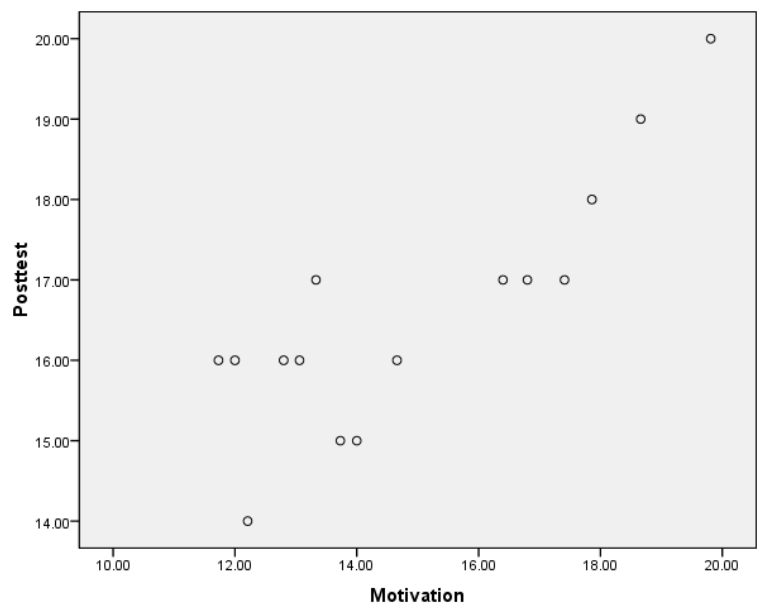

Figure 4.1 Scattergram depicting the correlation between ESA approach and motivation

As the figure depicts the link between the scores on speaking test and motivation is linear as the data points muster around an illusory straight line. Thus, it was appropriate to test for a linear relationship in the data by running a correlation analysis considering the said presupposition. On that account and as a general rule, the normality of distribution for speaking test and motivation scores provided evidence for utilizing Pearson's product-moment formula to calculate the extent of relationship between the two variables.

\subsubsection{Normality of Distribution}

In an attempt to examine the normality of the distribution, the descriptive statistics of the data were procured.

Table 4.9 Descriptive statistics of skewness and Kurtosis for speaking test and motivation scores

\begin{tabular}{|c|c|c|c|c|c|c|c|c|c|}
\hline & $\mathrm{N}$ & Minimum & Maximum & Mean & $\begin{array}{l}\text { Std. } \\
\text { Deviation }\end{array}$ & Skewness & & Kurtosis & \\
\hline & Statistic & Statistic & Statistic & Statistic & Statistic & Statistic & Std. Error & Statistic & Std. Error \\
\hline Speaking test & 15 & 14.00 & 20.00 & 16.6000 & 1.54919 & 649 & .580 & .623 & 1.121 \\
\hline Motivation & 15 & 11.73 & 19.81 & 14.9640 & 2.63626 & .483 & .580 & -1.154 & 1.121 \\
\hline $\begin{array}{l}\text { Valid } \\
\text { wise) }\end{array}$ & 15 & & & & & & & & \\
\hline
\end{tabular}


As it is illustrated in the above table, the distribution of the data for speaking test and motivation happened to be normal. According to the table, skewness ratios for speaking test and motivation are 1.11 and 0.83 respectively and kurtosis ratios for the two variables equal 0.55 and -1.02 respectively as well. Given that, all the ratios are set well within \pm 1.96 limits, suggesting that the departure from normality is not too extreme. Therefore the results prove the symmetrical distribution of the data being evenly clustered around the mean.

\subsubsection{Testing the Null Hypothesis}

Having determined that the data concerning both speaking test and motivation scores are evenly distributed, the Pearson's product-moment correlation coefficient (PPMCC) formula can be calculated to determine the degree of relationship between variables on that ground. The result is illustrated in the following table.

Table 4.10 correlation analysis of speaking posttest and speaking posttreatment questionnaire scores

\begin{tabular}{llll}
\hline & \multicolumn{1}{c}{$\begin{array}{l}\text { Speaking } \\
\text { Posttest }\end{array}$} & Motivation \\
\hline Speaking test Pearson Correlation & 1 & $.840^{* *}$ \\
& Sig. (2-tailed) & .000 \\
& $\mathrm{~N}$ & 15 & 15 \\
\hline Motivation & Pearson Correlation & $.840^{* *}$ & 1 \\
& Sig. (2-tailed) & .000 & \\
& $\mathrm{~N}$ & 15 & 15 \\
\hline **. Correlation is significant at the 0.01 level (2-tailed).
\end{tabular}

According to the table 4.10, correlation is significant at 0.01 level $(r=0.840, p<0.01)$. In the same manner, results of the analysis prove that the expected $\mathrm{p}$ value less than $0.01(\mathrm{p}<0.01)$ is strong evidence that the null hypothesis is rejected $(0.00<0.01)$. As a result, findings of the study rightly indicate that the implementation of ESA have a significant impact on promoting EFL learners motivation to speak.

\section{Discussion}

This study attempted to explore the possible impact of Harmer's ESA elements on motivation of EFL learners to speak. Thanks to the estimated reliability of test scores $(r=0.84)$ and $P$ value which was less than 0.01 , it can be concluded that implementation of ESA on tasks do have a significant impact on motivation of learners to speak. Consequently, With regard to the findings of the study obtained from the pre- post treatment questionnaire frequencies and correlational analysis of the speaking test scores and post-treatment questionnaire scores, it can genuinely be construed that the decorous implementation of ESA approach on tasks can promote learners speaking in general and their motivation in particular.

In probing the effect of ESA elements on speaking ability of EFL learners, Khoshsima, H and Shokri, H (2016, 2017) found out that this type of technique is quite utilitarian in the development of speaking proficiency of EFL learners. Correspondingly, the findings of the study are in congruence with the findings of the other researchers in this area. The results of the study are in agreement with the work of Chuang (2014). She described how the development and implementation of the technology- supported learning environment will be beneficial in student and instructor engagement and the overall learning motivation. She concluded that this environment can promote greater classroom engagement and support collaborative learning. The findings of the study are also comparable with the study by torrico (2015) who utilized drama technique in enhancing motivation of learners to speak. It was found out that drama activities foster students' interest in the subject and, consequently improve their speaking abilities. In another study whose results parallel the findings of this study, Naima (2013) examined the Role of Intrinsic Motivation in Developing the Students' Speaking Skill. This study utilized two questionnaires submitted to both students and teachers of oral expression. The analysis of the questionnaire showed that both learners and teachers consider intrinsic motivation as an important factor in enhancing the skill of speaking. In contrast, the findings of the study are in contrast with the work of Rahmany et al (2013) who found out that extensive reading did not have a significant effect on EFL learners' motivation for speaking.

\section{Conclusion}

Taking into account the fact that ESA can be regarded as one of the influential and effective instructional technique in teaching speaking to EFL learners, it can firmly be argued that proper use of this approach would significantly help teachers promote EFL learners motivation to speak. By claiming this, the advantageous of using this method will be unveiled. The first and foremost advantageous would be its ability to emotionally engage learners in teacher-led discussion tasks and subsequently the learning process. In this case, the content and topic of the lesson would be chosen according to students' interest. Therefore, acknowledging learners' needs seems indispensable in student participation and involvement in task completion. Additionally utilization of these task activity types invokes more talk, more even 
participation, more motivation and enjoyment. Another merit of implementing this type of instruction is its perspective toward student's performance. Here, students' performance is reinforced by doing pair and group work activities during the activation phase. It is during this phase of teaching where the learners correct their own (self-assessment) as well as their peers (peer assessment) mistakes in a socially and friendly situation. Inevitably, the teacher by monitoring students' performance receives feedback as to how much the learners have learned and where extra instruction is needed. The last but not the least would be the fact that this type of approach fully takes students motivation into account. This is accomplished through contextual influences either as a form of instructional context (e.g. task, topic, materials design and evaluation practices) or Social and cultural influences (e.g. pair and group work activities). As a result, the whole phase is planned carefully by the teacher to achieve outstanding and productive outcomes leading to students' active learning. Taking into account the abovementioned advantageous accruing from ESA, it can firmly be claimed that ESA approach can be regarded as the most progressive instructional approach in the field of EFL.

Regarding the correlational analysis carried out as to see the relationship between the learners' motivation and their speaking performance, the findings of the study obtained from the data analysis indicated that there was a significant positive relationship between the speaking performance and their motivation. Therefore, it can convincingly be argued that the employment of ESA elements would significantly influence students' motivation to speak.

The present research, although limited in scope, is specifically carried out to develop apprehension of employing ESA technique in promoting EFL learners motivation to speak. On that account, the findings of the study would offer considerable amount of courses of action and implications sine qua non for EFL teachers, EFL learners, syllabus designers, supervisors, material producers, textbook writers and researchers.

\section{References}

Binalet, C. B., \& Guerra, J. M. (2014). A Study on the relationship between motivation and language learning achievement among tertiary students. International Journal of Applied Linguistics and English Literature, 3(5), 251260.

Bonwell, C. C., \& Eison, J. A. (1991). Active learning: Creating excitement in the classroom. Washington, DC: School of Education and Human Development, George Washington University.

Brophy, J. (2004). Motivating Students to Learn (2 $2^{\text {nd }}$ ed.). London: Lawrence Erlbaum Associates.

Chuang, Y. T. (2014). Increasing learning motivation and student engagement through the technology-supported learning environment. Creative Education, 5(23), 1969.

Crookes, G., \& Schmidt, R. W. (1991). Motivation: Reopening the research agenda. Language learning, 41(4), 469512.

Deci, E. (1975) Intrinsic Motivation. New York: Plenum Press.

Dornyei, Z (2001). Motivational Strategies in the Language Classroom. Cambridge: Cambridge University Press.

Dörnyei, Z. \& Ottó, I. (1998) Motivation in action: A process model of L2 motivation. Working Papers in Applied Linguistics (Thames Valley University, London) 4: 43-69.

Dornyei, Z. \& Ushioda, E. (2011). Teaching and Researching Motivation (2 ${ }^{\text {nd }}$ ed). Malaysia: (C) Pearson Education Limited.

Elizabeth F. Barkley (2010). Student engagement techniques ( $\left.1^{\text {st }} \mathrm{ed}\right)$ : A Handbook for College Faculty. United States of America: John Wiley \& Sons.

Ellis, R. (1994). The Study of Second Language Acquisition. Oxford: Oxford University Press.

First Certificate in English (2008). Official Examination Papers from University of Cambridge ESOL Examinations. Cambridge: Cambridge University Press.

Gardner, R.C., \& Lambert, W.E. (1972). Attitudes and motivation: Second language learning. Rowley, MA: Newbury House.

Harmer, J. (2007). The changing world of English: In The practice of English language teaching. Cambridge: UK, Pearson Longman.

Hughes, R., \& Pace, C. R. (2003). Using NSSE to study student retention and withdrawal. Assessment Update, 15(4), 12.

Kinzie, J. (2010). Student engagement and learning: Experiences that matter. In Taking Stock: Research on Teaching and Learning in Higher Education (139-153). J. Christensen Hughes \& J. Mighty (Eds.), Kingston, Canada: School of Policy Studies, Queens University at Kingston.

Khoshsima, H., \& Shokri, H. (2016). The Effects of ESA Elements on Speaking Ability of Intermediate EFL Learners: A Task-based Approach. Theory and Practice in Language Studies, 6(5), 1085-1095. DOI: http://dx.doi.org/10.17507/tpls.0605.24

Khoshsima, H., \& Shokri, H. (2017). Teacher's Perception of Using ESA Elements in Boosting Speaking Ability of EFL Learners: A Task-based Approach. Journal of Language Teaching and Research, 8(3), 577-587. DOI: http://dx.doi.org/10.17507/jltr.0803.17 
Kuh, G. D. (2001). The National Survey of Student Engagement: Conceptual framework and overview of psychometric properties. Bloomington, IN: Indiana University Center for Postsecondary Research, 1-26

LAN, L. T. (2008). Factors affecting motivation in learning speaking English of grade 10 students at Yendinh 1 high school. Vietnam: ULIS. Retrieved on 23 July 2014 from:

http://tainguyenso.vnu.edu.vn/jspui/handle/123456789/5004

Lightbown, M.P., Spada, N. (1999). How Language are learned. Oxford: Oxford University Press.

Naima, B. (2013). The Role of Intrinsic Motivation in Developing the Students' Speaking Skill (Master's thesis). Retrieved on 16 June 2015 from:

http://dspace.univ biskra.dz:8080/jspui/bitstream/123456789/4756/1/THESIS.pdf

Nunan, D. (1999). Second Language Teaching and Learning. Boston, MA: Heinle and Heinle.

Prince, M. (2004). Does active learning work? A review of the research. Journal of Engineering Education, Washington, 93(3), 223-232.

Rahmany, R., Zarei, A. A., \& Gilak, S. (2013). The Effect of Extensive Reading on Iranian EFL Learners" Motivation for Speaking. Journal of Language Teaching and Research, 4(6), 1238-1246.

Shulman, L. (2002). Making differences: A table of learning. Change: The Magazine of Higher Learning, 34(6), 36-44.

Torrico, F. (2015). Drama techniques to enhance speaking skills and motivation in EFL secondary classroom. (Master's thesis). Retrieved on 16 July 2015 from: http://eprints.ucm.es/32553/1/TFM\%20\%281\%29.pdf

Tsui, A. B. M. (1996). Reticence and anxiety in second language learning. In K. M. Bailey and D. Nunan. (Eds.). Voices from the language classroom (pp. 145-167). Cambridge, UK: Cambridge University Press.

Ur, P. (1991). A course in Language Teaching. Cambridge: Cambridge University Press.

Maslow, A. (1970) motivation and personality ( $2^{\text {nd }}$ Ed). New York: Harper and Row.

Williams, J. D.; Friesen, S.; \& Milton, P. (2009). What Did You Do In School Today? Transforming Classrooms through Social, Academic and Intellectual Engagement. (First National Report). Canadian Education Association. Retrieved on 18 December 2013 from: http://www.cea-ace.ca/sites/cea-ace.ca/files/cea-2009-wdydist.pdf 